\title{
The new ways to increase the efficiency of thermal hydraulic processes in systems of separation and reheating of NPP wet steam turbines
}

\author{
Mikle Egorov ${ }^{1,2, *}$, Ivan Kasatkin ${ }^{1}$, Ivan Kovalenko ${ }^{2}$, Irina Krectunova ${ }^{1}$, Nataliya Lavrovskaya ${ }^{2}$, and Nadezhda Litvinova ${ }^{2}$ \\ ${ }^{1}$ Peter the Great St. Petersburg Polytechnic University, Russia, 195251 Saint-Petersburg, Polytechnicheskaya 29 \\ ${ }^{2}$ St. Petersburg State University of Aerospace Instrumentation, Russia, 190000 Saint Petersburg, Bolshaya Morskaya st. 67
}

\begin{abstract}
Systems of moisture separators - reheaters (SMSR) were created simultaneously with the powerful turbines development of nuclear power plants operating on a wet steam from the early 60 s of the 20th century. This lengthy experience made the opportunity to identify the moisture separators - reheaters (MSRs) drawbacks, to determine the objectives for their design and computation improvement in order to increase thermodynamic efficiency, MSR devices and MSR systems reliability in general. Based on maintenance experience and results of our and other researchers' model and field studies this article discusses potential ways of further development and improvement, taking into consideration both SMSR components (separation and reheating) under conditions of their flow in one apparatus.
\end{abstract}

\section{Introduction}

The moisture separation and reheating organisation of low-pressure steam in turbine units of nuclear power plants with water-cooled reactors is the problem, appeared with the steam turbines creation operating on saturated steam, i.e. simultaneously with the large-scale nuclear power advent in the USSR and in other countries (in early 1960s) [1]. The steam parameters are significantly lower than the standard reheated steam parameters of used in organic fuels power engineering. This does not apply to nuclear power installations with supercritical parameters that are promising, but have not been implemented yet. Despite measures, taken to dry saturated steam in separating devices of boiling reactors and steam generators to a moisture level of $y<(\sim 0.5) \%$, with the steam expansion in the flowing turbine part, it is humidified, and, if it is not dehydrated after the high pressure (HPP) part, then the humidity reaches values unacceptable for a turbine blade. Therefore, when steam reaches the so-called separation pressure, the steam is sent to special devices - moisture separators-reheaters (MSRs) [2-5]. They separate moisture from the steam and overheat the dried steam to a temperature that ensures reliable operation of the LP part. Overheating is carried out at the expense of the heat of the condensing high-pressure steam. Two-stage overheating is the most common at MSR of Soviet (Russian) design: in the first stage, due to the heat of the condensing steam withdrawn from the turbine's turbocharger, and in the second stage, due to the heat of the hot steam in front of the turbine.

MSR constructive schemes of Russian NPPs with water-cooled reactors that have been in operation since early 1970s (SPP-220-1, SPP-500, SPP-500-1, SPP-
1000, SPP-1000-1), are presented in table 1 [6]. Their main design parameters (NPP turbine is working at rated power) are shown in the table.

\section{Materials and methods}

\subsection{Some thermal-hydraulic processes features in MSR, revealed during their operation}

At the initial period of devices design, naturally, there was no their long-term operation experience. Moreover, many features of the medium flow processes, heat and mass transfer in them had not been sufficiently studied [7-10]. They were investigated only on smallscale models and did not take into account the scale factor, the geometry specifics of the systems and moisture separation and reheating processes [11-17]. Natural designers' tendency to maximize the devices' compactness (minimum metal capacity) made the problem even more complex. This, in particular, led to a constructive solution, consisting in the placement of both parts - separation and reheating - in one housing, which means that the device has:

- steam and water phases with moisture and vapor content varying from zero to one (dried reheated steam, condensate),

- zones with high velocities (up to $\sim 60 \mathrm{~m} / \mathrm{s}$ in the inlet steam part) and with low velocities $(\sim 0.4 \mathrm{~m} / \mathrm{s}$ at the condensate outlet of the heating steam),

- sections with high heat transfer $\left(\alpha \sim 15000 \mathrm{~W} /\left(\mathrm{m}^{2} \mathrm{~K}\right)\right.$ in the condensation zone of steam) and with relatively low $\left(\alpha \sim 300 \mathrm{~W} /\left(\mathrm{m}^{2} \mathrm{~K}\right)\right.$ for reheated steam.

All of the aforementioned processes create operating

Corresponding author: mikhail.yu.egorov@ gmail.com 
Table 1. . Design characteristics of Russian systems of moisture separators- reheaters (SMSR) operating at rated power.

\begin{tabular}{|c|c|c|c|c|c|c|c|c|c|}
\hline Power unit & \multicolumn{2}{|c|}{ WWER-440 } & \multicolumn{2}{|c|}{ RBMK-1000 } & \multicolumn{2}{|c|}{ RBMK-1000 } & \multicolumn{2}{|c|}{ WWER-1000 } & WWER-1000 \\
\hline Notation & \multicolumn{2}{|c|}{ SMSR-220 M } & \multicolumn{2}{|c|}{ SMSR-500 } & \multicolumn{2}{|c|}{ SMSR-500-1 } & \multicolumn{2}{|c|}{ SMSR-1000 } & SMSR-1000-1 \\
\hline Reheater tube types & \multicolumn{2}{|c|}{ finned } & \multicolumn{2}{|c|}{ smooth-tube } & \multicolumn{2}{|c|}{ smooth-tube } & \multicolumn{2}{|c|}{ finned } & finned \\
\hline $\begin{array}{l}\text { Stages' number; reheater } \\
\text { type }\end{array}$ & \multicolumn{2}{|c|}{$\begin{array}{c}2 ; \\
\text { straight-tube }\end{array}$} & \multicolumn{2}{|c|}{$\begin{array}{c}2 \\
\text { spiral coils } \\
\end{array}$} & \multicolumn{2}{|c|}{$\begin{array}{c}2 ; \\
\text { straight-tube }\end{array}$} & \multicolumn{2}{|c|}{$\begin{array}{c}2 ; \\
\text { straight-tube }\end{array}$} & $\begin{array}{c}1 ; \\
\text { straight-tube }\end{array}$ \\
\hline Thermal power, MW & \multicolumn{2}{|c|}{28.2} & \multicolumn{2}{|c|}{37.5} & \multicolumn{2}{|c|}{33.1} & \multicolumn{2}{|c|}{46.2} & 59.2 \\
\hline $\begin{array}{l}\text { SMSR number for one } \\
\text { turbine, pcs }\end{array}$ & \multicolumn{2}{|c|}{2} & \multicolumn{2}{|c|}{4} & \multicolumn{2}{|c|}{4} & \multicolumn{2}{|c|}{2 or 4} & 4 \\
\hline $\begin{array}{l}\text { Heating steam } \\
\text { (condensing): }\end{array}$ & \multicolumn{2}{|c|}{ in tubes } & \multicolumn{2}{|c|}{ in tubes } & \multicolumn{2}{|c|}{$\begin{array}{c}\text { in the intertubular } \\
\text { space }\end{array}$} & \multicolumn{2}{|c|}{ in tubes } & in tubes \\
\hline inlet temperature, ${ }^{\circ} \mathrm{C}$ & 206 & 253 & 210 & 278 & 210 & 278 & 228 & 272 & 272 \\
\hline pressure, $\mathrm{MPa}$ & 1.8 & 4.2 & 1.9 & 6.3 & 1.9 & 6.3 & 2.6 & 5.6 & 5.7 \\
\hline consumption, $\mathrm{kg} / \mathrm{s}$ & 8.92 & 7.50 & 9.08 & 11.6 & 8.75 & 11.7 & 13.7 & 17.7 & 36.1 \\
\hline Heated steam: & 1 stage & 2 stage & 1 stage & 2 stage & 1 stage & 2 stage & 1 stage & 2 stage & \\
\hline $\begin{array}{l}\text { inlet / outlet temperature, }{ }^{\circ} \\
\text { C }\end{array}$ & $136 / 189$ & $189 / 241$ & $137 / 197$ & $197 / 265$ & $137 / 192$ & $192 / 263$ & $185 / 208$ & $208 / 250$ & $157 / 250$ \\
\hline pressure, $\mathrm{MPa}$ & \multicolumn{2}{|c|}{0.304} & & 34 & 0.3 & 34 & 1. & 15 & 0.567 \\
\hline $\begin{array}{l}\text { steam consumption at the } \\
\text { inlet, } \mathrm{kg} / \mathrm{s}\end{array}$ & & & 1 & 88 & 12 & 14 & 32 & 8 & 313 \\
\hline $\begin{array}{l}\text { humidity at the inlet of } \\
\text { SMSR, \% }\end{array}$ & & & 15 & .5 & 15 & .0 & 11 & .6 & 14.2 \\
\hline $\begin{array}{l}\text { humidity at the outlet of } \\
\text { the separator, } \%\end{array}$ & & & & & $<(\sim$ & $0.5)$ & $\sim 0$ & .5 & $\sim 0.5$ \\
\hline Total SMSR height , $\mathrm{m}$ & & & 6. & 71 & 9. & 05 & 13 & 35 & 14.60 \\
\hline Case diameter (internal), $\mathrm{m}$ & & & 4. & 15 & 4. & 13 & 3. & 44 & 4.00 \\
\hline $\begin{array}{l}\text { Steel grade of housing } \\
\text { material / tubes }\end{array}$ & $16 \mathrm{G}$ & & $08 \mathrm{H} 18$ & $\mathrm{~N}_{10 \mathrm{~T}}{ }^{4}$ & $08 \mathrm{H} 18$ & $\mathrm{~N} 10 \mathrm{~T}^{4}$ & $22 \mathrm{~K}$ & $/ 20^{3}$ & $22 \mathrm{~K}^{3} / 20^{3}$ \\
\hline Heating tube bundle: & & & & & & & & & \\
\hline diameter, $\mathrm{mm}$ & & & $18 \mathrm{x}$ & 1.4 & $14 \mathrm{x}$ & 1.2 & 16 & $\mathrm{x} 2$ & $16 \times 2$ \\
\hline length, $\mathrm{m}$ & & & 90 & 102 & 2. & 0 & 4 & 6 & 3.9 \\
\hline number, pcs. & 3478 & 3441 & 432 & 216 & 14760 & 17640 & 2960 & 3959 & 8288 \\
\hline $\begin{array}{l}\text { overheating cassettes } \\
\text { (modules) number, pcs. }\end{array}$ & 94 & 93 & spira & coils & 60 & 70 & 80 & 103 & 224 \\
\hline $\begin{array}{l}\text { Tubes number in the } \\
\text { cassette (module), pcs. }\end{array}$ & & & & - & 25 & 54 & 3 & 7 & 37 \\
\hline $\begin{array}{l}\text { Weight of dry apparatus / } \\
\text { case, } t\end{array}$ & 110 & & 10 & $/ 23$ & 119 & $/ 38$ & 128 & $/ 40$ & $152 / 79$ \\
\hline Weight of tubes, $\mathrm{t}$ & & & & 0 & 5 & 0 & 2 & 2 & 27 \\
\hline Hydraulic resistance, $\mathrm{kPa}$ & & & & .7 & 22 & 6 & 33 & 4 & 16.3 \\
\hline $\begin{array}{l}\text { Mass ratio to thermal } \\
\text { power, t / MW }\end{array}$ & & & & 80 & 3. & 15 & 2. & 48 & 2.58 \\
\hline $\begin{array}{l}\text { The ratio of the overall } \\
\text { volume to the thermal } \\
\text { output, } \mathrm{m}^{3} / \mathrm{MW}\end{array}$ & & & & 74 & 3. & 28 & 2. & 46 & 2.50 \\
\hline
\end{tabular}

modes that decrease efficiency and the device reliability, leading to:

1) erosion and vibration wear of the separation devices, see Figure 1, showing the wear of the separation unit of Kalininskaya NPP [18];

2) increased moisture of vapor at the separation devices' outlet, see Figure 2, where the moisture after the separation units at Smolensk and Kursk NPPs [19] is compared with its design value;

3 ) lower temperature of the working vapor of low pressure in comparison with the design values, see Figure 3, where the output temperature of superheated steam at Leningrad NPP [20] is compared with its design value;

4) unstable flow of heating steam condensate, see Figure 4, which shows the development of fluctuations in condensate flow [21]. The condensate supercooling below the saturation temperature causes temperature pulsations of the heat exchange surfaces, thermal cyclic stresses and heat fatigue damages in welded joints and other reheater elements;

5) separator accumulation at the apparatus bottom and / or casting of the separated moisture portion into the supply or the reheater discharge tubes, having much higher temperature (see Table 1). 

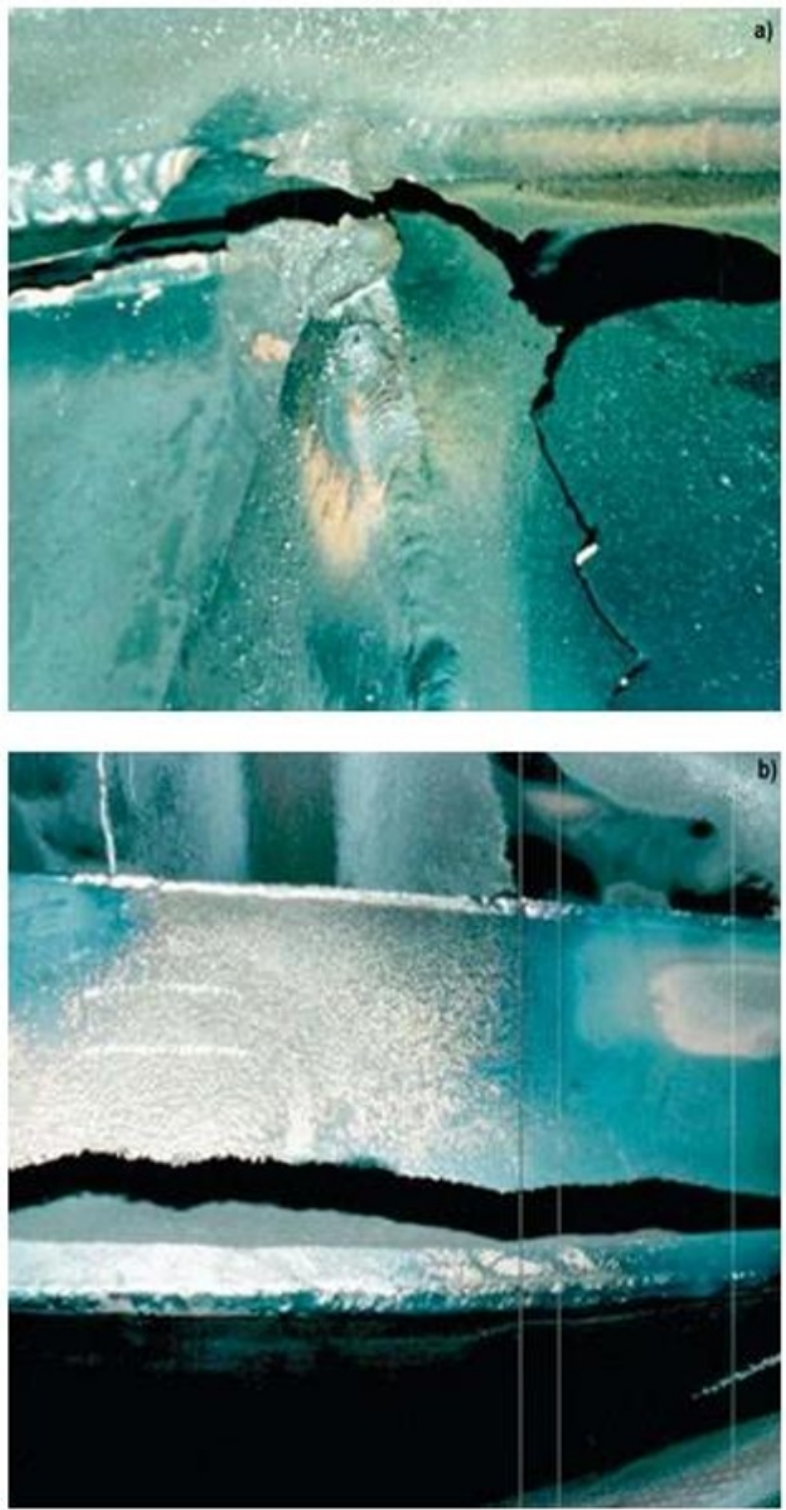

Fig. 1. Erosion wear of the separation unit, SMSR, Kalinin NPP [18]: a) - block adjacent to the hull, b) - bottom view.

The impact of these negative consequences usually appears only after a number of years of SMSR operation. As a result, it turned out that the actual overhaul SMSR life is significantly lower than the planned one.

All the mentioned factors and operating conditions should be taken into account when designing devices at the stage of their thermal and hydraulic calculations. We present below some factors analysis, emphasizing factors detected during long-term (during 30-40 years) operation at Russian NPPs with boiling reactors such as RBMK1000 with SMSR-500-1.

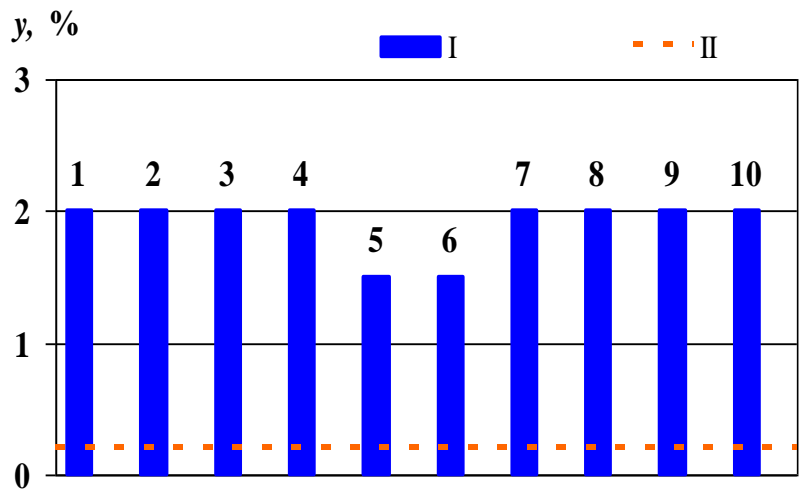

Fig. 2. Moisture (y) behind the separation units at the turbine units of Smolensk NPP (1-6), 6 turbines and Kursk NPP (7-10), 4 turbines: I - values according to the working data [19]; II project value.

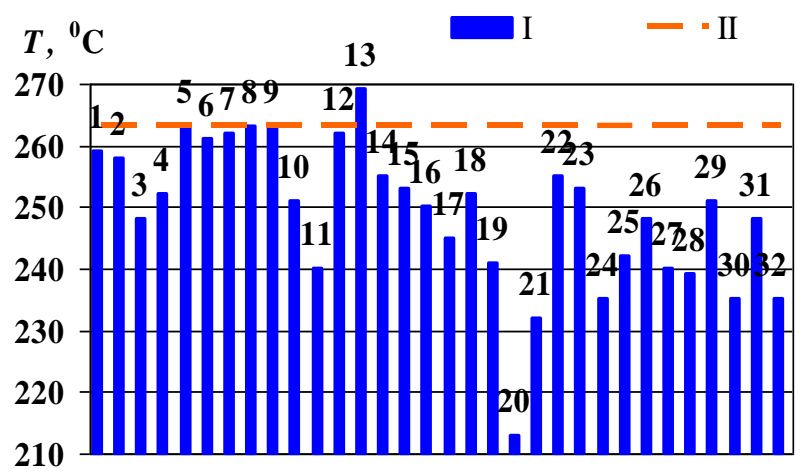

Fig. 3. The temperature of reheated steam of low pressure at the output of SMSR: I - actual [20]; II - design, Leningrad NPP.

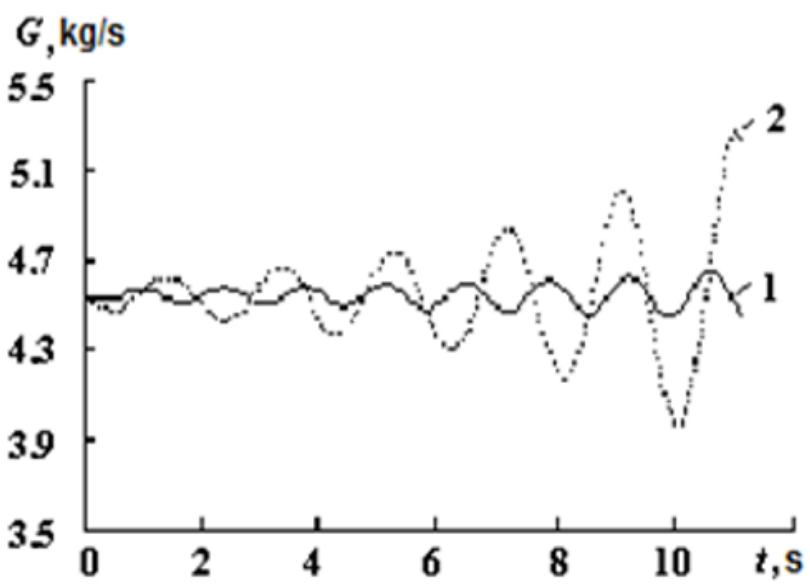

Fig. 4. Estimated evaluation of the development of selfoscillations of the condensate flow at the outlet of the reheater tube: the height of the condensate column in the tube is $1-l_{k}=$ $0.3 \mathrm{~m} ; 2-l_{k}=0.9 \mathrm{~m} \mathrm{[21]}$.

\section{Results and Discussion}

\subsection{Analysis of the ways to increase the efficiency of thermal hydraulic processes}

The common problem of designing and calculating the 
separation part of all SMSR, and SMSR-500-1 in particular, is the organization of moisture uniform distribution and vapor flows between separation devices.

Another problem is to ensure stable discharge of the separator from the SMSR. The path of the separator evacuation is one of the links in the general system for separating the moisture from the steam, draining it down into the separating cavities and unimpeded removal into a special container - separator collector. Problems in operation of this system, i.e. if there are fluctuations in consumption, steam inclusions capture, and water effervescence with a drop in pressure, etc., decreases effectiveness of the apparatus separation part as a whole. Poor quality of separator removal leads to the abovementioned possibility of contact with the reheater tubes, which is especially characteristic for devices with an upper separation part (SMSR-220-1, SMSR-500, SMSR500-1, SMSR-1000). Placing separation bags at the bottom of the device, as applied at SMSR-1000-1, significantly reduced the damage to the system.

Motion of the steam-moisture flow in the inlet chamber is rather complicated and occurs under conditions of significant influence of the mass forces. In spite of the small characteristic size of the water droplets, their trajectories can differ substantially from the steam current lines. Up to date none of the popular software packages have tools for solving this kind of tasks.

In Russia V.A. Barilovich, L.I. Zaichik, I.V. Derevich and others scientists were developing approaches to solving motion of two-phase disperse flows problems [22-23]. L.I. Zaychik and I.V. Derevich offered successful approach for aerosol flows, where deviations from homogeneity are not very high.

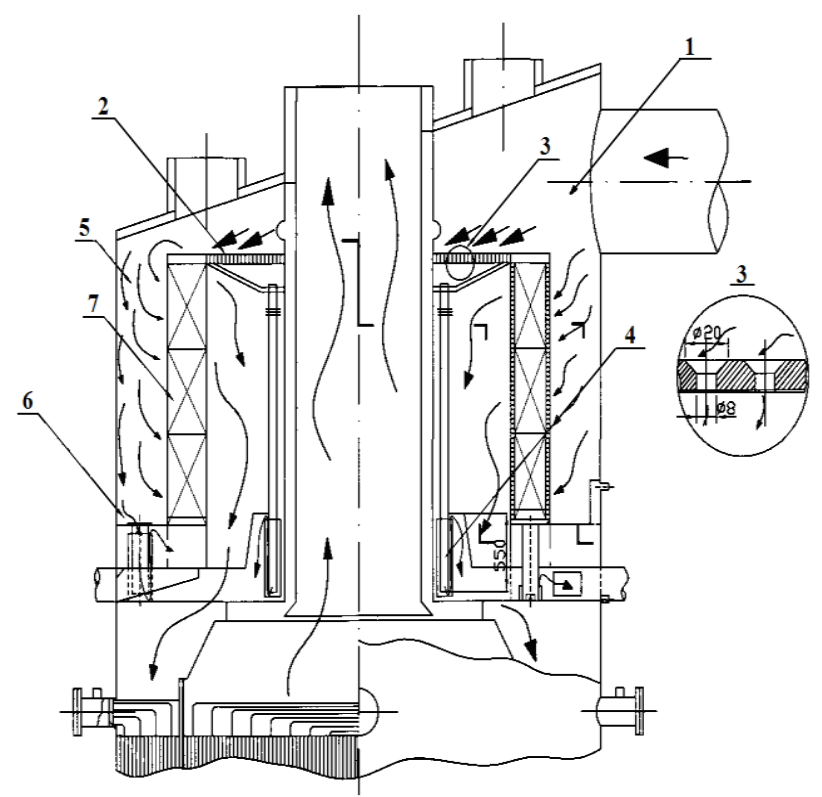

Fig. 5. General view of the modernized separation part SMSR500-1: 1 - entrance chamber, wet steam inlet; 2 - perforated plate; 3 - holes with openings; 4 - openings for taking the separator from the perforated plate, 6 pcs.; 5 - drainage of moisture from the walls of the inlet chamber; 6 -openings for taking the separator into an external annular collector, 6 pcs.; 7 - separation blocks.
For the streams formed in the input chamber SMSR500-1, Figure 5, the formation of liquid films and their subsequent destruction significantly complicates the solution of two-phase disperse flows problem.

Unfortunately, present day designers use solutions obtained in homogeneous approximation. Due to the complexity and originality of the two-phase flow regimes in the separation part of the SMSR it is advisable to carry out additional experimental research [24], as, for example, it was done when developing the upgraded version of SMSR-500-1 [25-26].

\section{Conclusion}

1. Analysis of Russian material constructions accumulated over the years of long-term operation of SMSR has revealed the features of the workflow that affect the efficiency and reliability of both the SMSR itself and the SMSR system as a whole. It is established that opportunities to intensify and improve the thermal and hydraulic characteristics of SMSR systems at Russian NPPs are not fully used.

2. The paper analyzes features of thermal-hydraulic processes in SMSR systems and the adverse consequences that have been manifested in the course of long-term operation, caused by insufficient consideration of these features.

3. In this article we also looked at the characteristic aspects of design improvement, leading to the enhancement of thermal and hydraulic processes, and the concept of the whole SMSR apparatus and its elements.

4. Regulatory materials that are newly created or updated need to include requirements that preclude the transfer of the separator to the reheater and the pulsation of the supercooled condensate flow.

5. It is important to eliminate the unevenness in both calculations and in SMSR tests. It is necessary to ensure equalization of the velocity field at the perimeter of the inlet chamber, the separating devices and the separating pipeline for heated steam. It is required to ensure the equalization of the distribution of the heating steam flow at reheater modules.

6. The upper location of the separator in the SMSR is undesirable for reliability reasons, since this eliminates the contact of the separator with the supply and removal tubes of the heating steam.

\section{References}

[1] A. Ulasen, A. Kalyutik, A. Blagoveshchenskii, MATEC Web Conf 245 (2018)

[2] L. Liu, B. Bai, Nuclear Engineering and Design 298, 229 (2016)

[3] P. Peceny, M. Kolovratnik, International Journal of Engineering XI, 4 (2013)

[4] J. Manabe, 22 ${ }^{\text {nd }}$ Intern. Conference on Nuclear Engineering ICONE22-30297 V02AT09A038 (2014)

[5] V.V. Legkostupova, A.V. Sudakov, Matec Web of Conferences 23, 01058 (2015) 
[6] A.V. Sudakov, B.S. Fokin, Steam generators and heat exchanging equipment of NPPs ( $\mathrm{SPb}, \mathrm{NPO}$ CKTI, 2005)

[7] N.D. Agafonova, I.L. Paramonova, Thermal Engineering 60, 3 (2013)

[8] S. Alekseev, Y. Ilyukhin, V. Kukhtevich, I. Paramonova, S. Svetlov, V. Sidorov, High Temperature 37, 4 (1999)

[9] N.D. Agafonova, I.L. Paramonova, Thermal Engineering 61, 8 (2014)

[10] N.D. Agafonova, I.L. Paramonova, Journal of Engineering Physics and Thermophysics 89, 4 (2016)

[11] G. Li, Ch. Yan, J. Wang, Annals of Nuclear Energy 73 (2014)

[12] M. Le, J. Kim, J. Kim, H. Do, J. Lee, Nondestructive Testing and Evaluation 33, 1 (2018)

[13] R. Rafee, H. Rahimzadeh, Iranian Journal of Chemistry and Chemical Engineering 29, 3 (2010)

[14] E. Narimani, S. Shahhoseini, Applied Thermal Engineering 31, 2 (2011)

[15] H. Zhang, Q. Liu, B. Qin, H. Bo, Annals of Nuclear Energy 75 (2015)

[16] X. Wang, P. Cheng, J. Xie, Z. Zhou, Journal of Mechanical Science and Technology 29, 8 (2015)

[17] F. Kavousi, Ya. Behjat, Sh. Shahhosseini, Chemical Engineering Research and Design 91 (2013)

[18] V. Solomeev, Rosenergoatom 7 (2006)

[19] N. Davidenko, V. Solomeev, P. Kruglikov, Thermal Engineering 1 (2008)

[20] V.V. Legkostupova, A.V. Sudakov, Thermal Engineering 62, 3 (2015)

[21] A. Kozlov, Proc. of the Odessa Polytechnic university 15 (1998)

[22] L. Zaichik, Proc. of the 2nd Russian Nat. Conf. on Heat Transfer 1 (1998)

[23] V.A. Barilovich, Bases of thermogasdynamics of two-phase flows and their numerical solution (SPb, Polytechnic University Press, 2009)

[24] M. Le, J. Kim, J. Kim, H. S. Do, J. Lee, Nondestructive Testing and Evaluation 33, 35 (2018)

[25] V.V. Legkostupova, A.V. Sudakov, St. Petersburg Polytechnic University Journal of Engineering Science and Technology 4, 254 (2016)

[26] V.V. Legkostupova, A.V. Sudakov, St. Petersburg Polytechnic University Journal of Engineering Science and Technology 23, 3 (2017) 